\title{
Unusual cause of thigh abscess in infant following hepatitis B vaccine administration
}

\author{
Sabit Numan Kuyubaşa**, Eyup Cagatay Zengina ${ }^{a}$, Alper Çırakııa, Sevgi Çıraklı \\ ${ }^{a}$ Department of Orthopedics and Traumatology, Faculty of Medicine, Ondokuz Mayls University, Samsun, Turkey \\ ${ }^{b}$ Department of Pediatrics, Faculty of Medicine, Ondokuz Mayls University, Samsun, Turkey
}

\section{ARTICLE INFO}

\section{Article History}

Received $\quad 05 / 02 / 2013$

Accepted $\quad 11 / 02 / 2013$

\section{* Correspondence to:}

Sabit Numan Kuyubaş1

Department of Orthopedics and Traumatology,

Faculty of Medicine,

Ondokuz Mayıs University, Kurupelit,

Samsun, Turkey

e-mail: s.numankuyubası@hotmail.com

\section{ABSTRACT}

A 30 days old healthy male infant with left thigh swelling was presented to our clinic by his family. Parents gave no history of diseases or trauma and was administered hepatitis B vaccine from left thigh one week before. Physical exam revealed approximately $3 \times 2$ $\mathrm{cm}$, erythematous, indurated, tender to palpation, fluctuating soft tissue swelling over the anterolateral left thigh. During needle puncture, $15 \mathrm{cc}$ purulent liquid was aspirated. As the liquid was purulent, irrigation and debridement were performed. Following six weeks of antibiotic treatment, the patient was completely recovered.

J. Exp. Clin. Med., 2013; 30:181-182

\section{Keywords:}

Abscess

Adverse effects

Hepatitis B vaccines

(C) 2013 OMU

Surgery

\section{Introduction}

Hepatitis B vaccine is considered as quite a safe vaccine among current vaccines (Sahin et al., 2011). Although complications are expected such as pain in administration area or mild fever following hepatitis B (3\%-9\%), severe side effects are very rare (Sahin et al., 2011). For development of side effects following vaccine administration, administration age, quality of vaccine, administration area and technique are very important (Namshan et al., 2011). The factors associated to administration technique are the most important causes in development of post vaccine complications (Namshan et al., 2011). In this case presentation, we discussed a case presented to our clinic with a swelling in thigh following hepatitis B vaccine administration.

\section{Case}

A 30-days-old healthy male infant with left thigh swelling was presented to our clinic by his family. Parents gave no history of diseases or trauma and was administered hepatitis B vaccine from left thigh one week before. His symptoms started following vaccine administration and they were referred to our clinic as swelling in thigh was grown progressively, redness developed and infant had difficulty moving his extremity. Physical exam ination revealed approximately $3 \times 2 \mathrm{~cm}$, erythematous, indurated, tender to palpation, fluctuating soft tissue swelling over anterolateral left thigh (Fig. 1). Heat increase was detected over lesion. Vital signs were normal. Laboratory tests showed that white blood cells (WBC) $15.2 \times 10^{9} / \mathrm{L}$, sedimentation rate $25 \mathrm{~mm} / \mathrm{h}, \mathrm{C}$ reactive protein (CRP) $71 \mathrm{mg} / \mathrm{L}$. Direct radiography showed no lesion except soft tissue swelling. Superficial tissue ultrasonography demonstrated $44 \times 31 \times 80 \mathrm{~mm}$, dense collection which was extended to distal femur, not in connection with the knee joint, abscess- hematoma differentiation could not be made, in the left anterior femur.

After making thigh abscess initial diagnosis, sterile needle puncture was performed to fluctuating soft tissue in operation room. During needle puncture, $15 \mathrm{cc}$ purulent liquid was aspirated (Fig. 2). As the liquid was purulent, irrigation and debridement were performed (Fig. 3). The culture of aspirated fluid was resulted with Staphylococcus aureus. Based on Pediatric Infectious Disease consultant recommendations, cefotaxime, metronidazole and teicoplanin treatment were given for six weeks. Complete recovery was achieved after three month- follow up. 


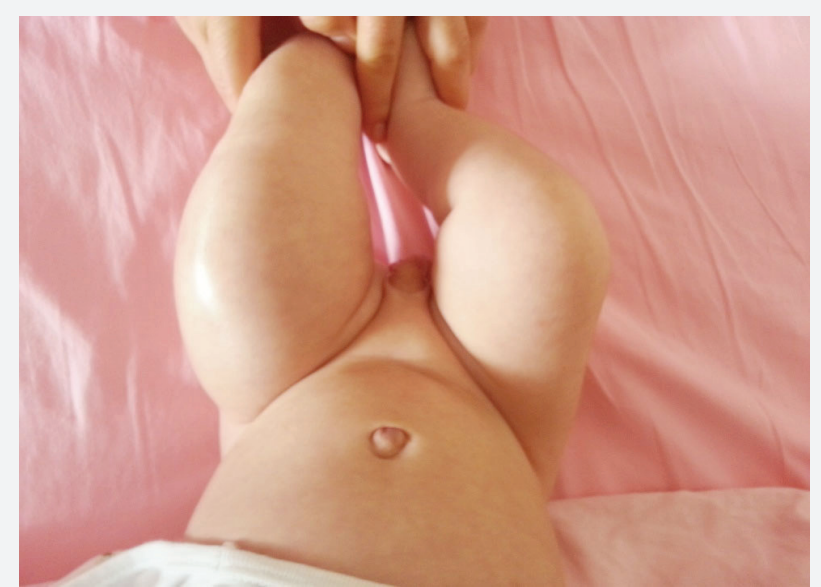

Fig. 1. Soft tissue swelling over left thigh.

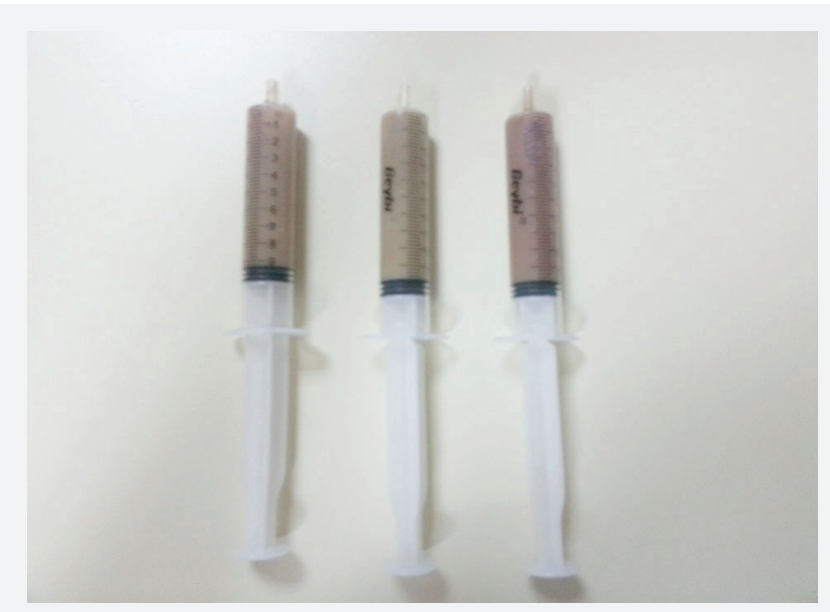

Fig. 2. 15 cc purulent liquid was aspirated with needle puncture.

\section{Discussion}

Hepatitis B vaccine is a highly safe and efficient vaccine commonly used in all around the world. While pain and swelling in injection area and subfebrile fever are most commonly seen among side effects, these findings often limit themselves (Sahin et al., 2011). Systemic side effects are less common. Side effects caused by vaccine injection are more commonly

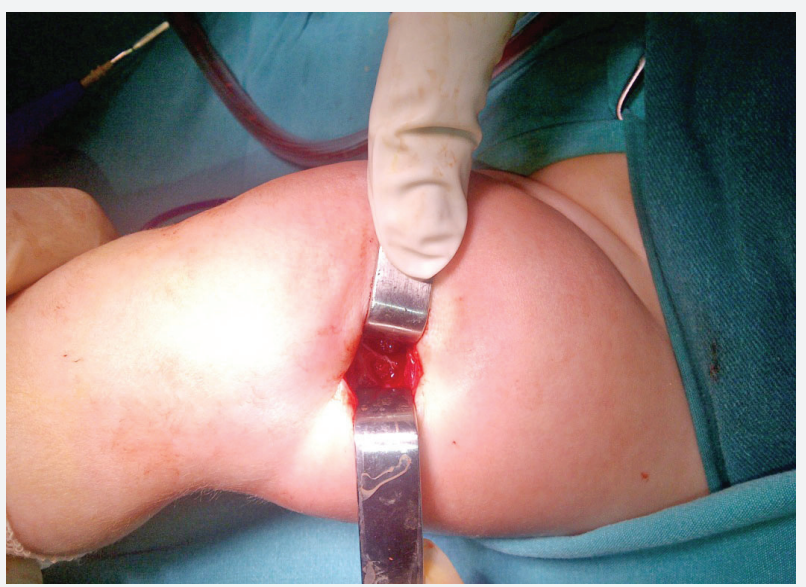

Fig. 3. Incision and drainage of the abscess.

seen when it is administered especially in the areas with low sociocultural level and without adequate logistic support by health personnel with insufficient training. Vaccine injection to wrong side for age, inaccurate doses, use of inaccurate dilution liquids and administration of non-sterile injectors may lead to soft tissue infection (Namshan et al., 2011). Technical factors are the most important causes in post vaccine complication development (Namshan et al., 2011). For achieving optimal effect of vaccination and prevention from unnecessary local and systemic effects, vaccine should be administered via suggested route. Abscess in vaccine area may be related to use of bacterial contaminated needle and injectors or it can also be seen as sterile abscess due to subcutaneous administration of especially adjuvant containing vaccines instead of intramuscular or inappropriate preparation of vaccine and poor storage conditions (Namshan et al., 2011). Akdeniz et al. (2006) reported that post hepatitis B vaccine side effects were least seen in the subcutaneous injection group, most in intramuscular injection group. We believe that the abscess in this case was caused by use of inappropriate vaccination technique without paying attention to sterility. In conclusion, we think that use of appropriate techniques during vaccine injection is the most important step to prevent development of vaccine related side effects.

\section{REFERENCES}

Akdeniz, H., Karahocagil, M.K., Karsen, H., 2006. Comparison of response results to low dose alternative intradermal and subcutaneous vaccine applications with the results of classical intramuscular vaccination route. Van Tip Dergisi. 13, 28-35.

Namshan, M.A., Oda, O., Almaary, J., Jadaan, S.A., Crankson, S., Banyan, E.A., Shaalan, M.A., Zamakhshary, M., 2011. Bacillus CalmetteGuérin-related cold thigh abscess as an unusual cause of thigh swelling in infants following BCG vaccine administration: A case series. J. Med. Case Rep. 5, 472-473.

Sahin, S., Durmaz, Y., Yakınc1, C., 2011. The comparison of antibody titers secondary to intramuscularly, subcutaneous or intradermal application of low dose Hepatitis B vaccine. J. Clin. Exp. Invest. 2, 277-281. 